УДК 685.5.011

В.Ю. Зінченко, к.т.н., доцент, elelna.zinchenko@mail.ru

B.I. Іванов, ст. наук. співробітник, colourmet@zgia.zp.ua

О.I. Чепрасов, к.т.н., професор, a.i.cheprasov@

Ю.М. Каюков, к.т.н, доцент, lenajura2010@gmail.com

Запорізька державна інженерна академія, м. Запоріжжя

\title{
ДО ОПТИМІЗАЦІЇ УПРАВЛІННЯ ТЕПЛОВОЮ РОБОТОЮ ПОЛУМЕНЕВИХ ТЕРМІЧНИХ ПЕЧЕЙ КАМЕРНОГО ТИПУ ПІД ЧАС НАГРІВАННЯ МАСИВНИХ ЗЛИВКІВ
}

Виконано аналіз відомих методів оптимізаиії процесу нагрівання масивних зливків під час термічної обробки у полуменевих термічних печах камерного типу. Запропоновано математичну модель, яка дозволяє без розв 'язання диференціальних рівнянь теплопровідності розробити алгоритм розрахунку температури нагрівального середовища за часом, що забезпечує заданий розподіл температури щодо перерізу зливків за термічної обробки з двома та більше рівнями постійності.

Ключові слова: полуменева піч камерного типу, масивні зливки, нагрівання під термічну обробку, математична модель, оптимізачія теплової роботи.

The analysis of the known methods for optimization of massive bars heating process at thermal treatment in the flaming thermal furnaces of chamber type is carried out. A mathematical model, allowing without the decision of differential equations of heat conductivity to work out the calculation algorithm for temperature of warming medium in time, which provides the given distribution of temperature on the section of bars at thermal treatment with two and anymore the levels of constancy is offered.

Keys words: flaming furnace of chamber type, massive bars, heating at thermal treatment, mathematical model, optimization of heating word.

\section{Постановка проблеми у загальному вигляді}

В умовах безперервного зростання ринкової вартості енергоносіїв, обмеження споживання природного газу та, як наслідок, зниження економічної ефективності енергоємних теплотехнологічних процесів особливо актуальною $є$ задача економії всіх енергоресурсів, і в першу чергу, природного газу в металургійному виробництві, де його головними споживачами $є$ камерні нагрівальні та термічні печі.

Полуменеві термічні печі камерного типу набули найбільшого поширення через універсальність щодо видів теплової обробки різних за формою та масою зливків, але $є$ економічно неефективними агрегатами. 3 огляду на те, що конструкції цих печей являються фізично та морально застарілими основним завданням визначено вдосконалення управління полями температури у робочому об'ємі печей, рухом нагрівальних газів, а також оптимізація теплової роботи у цілому [1].

\section{Аналіз останніх досягнень і публікацій}

Відомо, що для печей цього типу температурно-часові режими обробки задають не лише для забезпечення заданого рівня температури поверхні металу та рівномірного ії розподілу щодо перерізу, але й для досягнення теплофізичних перетворень у металі під час термічної обробки. Такі режими нерідко $є$ багатоступеневими з обмеженням, як за швидкістю нагрівання, так і охолодження металу. За роботи вказаних печей спостерігають складнощі щодо забезпечення рівномірного підведення теплоти до поверхні зливків, оскільки процес вирівнювання температури металу відбувається за безперервним зниженням теплового потоку, що пов'язано 3 додержанням на поверхні металу заданого рівня температури. До кінця періоду нагрівання металу, у міру зниження загальної витрати пічних газів, що нагрівають метал, i, як наслідок, зниження швидкості їх руху в робочій камері печі, значення сумарного коефіцієнта тепловіддачі зменшується, що призводить до ускладнення організації процесу нагрівання металу. 
Під час розробки раціональних температурно-часових режимів нагрівання металу під термічну обробку широко застосовують їх автоматичне моделювання. У автоматизованих системах управління зазначеним процесом математичні моделі застосовують:

- за відсутності засобів інструментального контролю якості нагрівання металу для оцінки його поточних показників за результатами вимірювання інших величин, що піддаються контролю [2,3];

- за математичної оптимізації процесу нагрівання металу для отримання алгоритмів управління, оптимальних щодо певних критеріїв $[4,5]$;

- за визначенням раціональних конструктивних параметрів печей, розробки технологічних інструкцій нагрівання металу під термічну обробку [6,7];

- за дослідженням нештатних ситуацій, коли виконання експериментів на практиці фізично або технічно є неможливим [8,9].

Моделі першого та четвертого типу відносять до задач аналізу з визначенням за відомими геометричними, фізичними та крайовими умовами полів температури (пряма задача теплопровідності), моделі другого та третього типу — до задач синтезу зі знаходженням крайових умов або параметрів системи щодо заданого розподілу температури у металі, що нагрівають (обернена задача теплопровідності).

Аналітичне розв’язання нелінійних задач конвективно-радіаційного теплообміну за нестаціонарної температури нагрівального середовища має суттєві складнощі. Так, через нелінійну залежність теплофізичних параметрів металу від температури, лінійні диференціальні рівняння можуть бути використаними під час моделювання нагрівання у вузькому діапазоні температури для печей безперервної дії. Для полуменевих термічних печей камерного типу із змінним у часі температурним режимом такі рівняння стають нелінійними і не мають єдиного розв'язання.

Таким чином, вирішення задачі оптимізації процесу нагрівання металу під термічну обробку в печах цього типу ускладнюється відсутністю простої математичної моделі, що визначає залежність кінцевих показників якості нагрівання металу від дій, що управляють, у системі «нагрівальні гази - кладка - метал». Відомі методи оптимізації такого процесу на основі розв'язання складних диференціальних рівнянь теплопровідності не забезпечують реального характеру розподілу температури щодо перерізу термічно оброблюваних зливків, а також за висотою та шириною робочого об'єму печей.

\section{Формулювання мети дослідження}

Завданням цієї роботи є побудова математичної моделі нагрівання масивних зливків, що дозволяє без розв'язання диференціальних рівнянь теплопровідності розробити алгоритм змінювання температури нагрівального середовища у часі, який забезпечує заданий розподіл температури щодо перерізу металу, що нагрівають, з можливістю ідентифікації самої моделі.

\section{Виклад основного матеріалу}

На етапі вирішення задачі, пов'язаної з оптимізацією нагрівання термічно масивних зливків у печах даного типу, переважно, встановлюють взаємозв'язок дії, що управляс, — температури нагрівального середовища $T_{\mathrm{w} . e .}$ i вихідних змінних параметрів процесу: температури поверхні металу $T_{\text {sur }}$, його середньомасової температури $\bar{T}_{\mathrm{m}}$ та перепаду температури між поверхневими і серединними шарами металу $\Delta T_{\mathrm{m}}$, що нагрівають, а також часу його нагрівання $\tau$. Вказані параметри $\epsilon$ взаємозв'язаними та визначаються функцією розподілу температури щодо перерізу зливків та у часі $T(x, \tau)$.

Проте аналітичний опис розподілу температури щодо перерізу металу, що нагрівають, i в часі $\square$, що отримано під час розв' язання класичного диференціального рівняння теплопровідності із завданням крайових умов, виявляється незручним для практичного використання [10], оскільки не вдається довести його без втрат до чисельних значень і для практичних задач використовують експоненціальну залежність виду:

$$
T\left(x, \tau_{\text {fix }}\right)=T_{\text {sur }}\left(\tau_{\text {fix }}\right) \cdot \exp \left[-\gamma\left(\tau_{\text {fix }}\right) \cdot x\right],
$$


де $T\left(x, \tau_{\text {fin }}\right)$ - розподіл температури у металі за координатою $x$ на фіксований момент часу $\tau_{\text {fin }} ; T_{\text {sur }}\left(\tau_{\text {fix }}\right), \gamma\left(\tau_{\text {fix }}\right)-$ температура поверхні металу, що нагрівають, і показник ступеня експоненти на момент часу $\tau_{\text {fix }}$ відповідно.

Тому розподіл температури за координатою $x$ задають функцією з одним параметром, що настроюють $\tau_{\text {fix }}$

$$
\gamma\left(\tau_{\text {fix }}\right)=\frac{1}{S} \cdot \ln \left[\frac{T_{\text {sur }}\left(\tau_{\text {fix }}\right)}{T_{\text {sur }}\left(\tau_{\text {fix }}\right)+\Delta T_{\mathrm{m}}}\right] .
$$

Точність апроксимації оцінюють зіставленням з результатами чисельних розрахунків розподілу температури $T(x, \tau)$. Розглядали одномірну задачу нагрівання масивного зливка товщиною $S$ з постійними коефіцієнтом теплопровідності $\lambda_{\mathrm{m}}$, питомою теплоємністю $c_{\mathrm{m}}$ і щільністю металу $\rho_{\mathrm{m}}$ :

$$
\begin{gathered}
\frac{\partial T(x, \tau)}{\partial \tau}=a_{\mathrm{m}} \frac{\partial^{2} T(x, \tau)}{\partial x^{2}} ; \\
-\left.\lambda_{\mathrm{m}} \frac{\partial T(x, \tau)}{\partial \tau}\right|_{x=0}=\alpha_{\Sigma} \cdot\left[T_{\mathrm{w} . \mathrm{e}}(\tau)-T_{\mathrm{m}}(\tau)\right] \\
\left.\frac{\partial T(x, \tau)}{\partial \tau}\right|_{x=S}=0 ; \\
T(x, 0)=T_{\mathrm{m}, 0}(x),
\end{gathered}
$$

де $T_{\mathrm{w} . \mathrm{e}}(\tau), T_{\mathrm{m}}(\tau)$ - поточні значення температури нагрівального середовища та поверхні металу відповідно; $a_{\mathrm{m}}$ - коефіцієнт температуропровідності, $a_{\mathrm{m}}=\lambda_{\mathrm{m}} / c_{\mathrm{m}} \cdot \rho_{\mathrm{m}} ; T_{\mathrm{m}, 0}(x)-$ функція розподілу температури металу за координатою $x$ на початковий момент часу.

Розв'язання рівняння теплопровідності (3) з крайовими умовами (4)-(6) виконують методом кінцевих різниць.

Для визначення залежності температури поверхні металу $T_{\text {sur }}$ від температури нагрівального середовища $T_{\mathrm{w} . \mathrm{e}}$ виконували підставляння функції (1) до граничної умови (4):

$$
T_{\text {sur }}\left(\tau_{\text {fix }}\right)=\frac{\operatorname{Bi} \cdot T_{\text {w.e }}}{\operatorname{Bi} \pm \gamma\left(\tau_{\text {fix }}\right) \cdot S}
$$

де $\mathrm{Bi}=\alpha_{\Sigma} / S \cdot \lambda_{\mathrm{m}}, \alpha_{\Sigma}-$ сумарний коефіцієнт тепловіддачі, Вт/(м.К), знак «土» визначає нагрівання або охолодження металу відповідно.

За результатами розрахунків, виконаних для нагрівання зливка товщиною 0,8 м при температури печі $1160{ }^{\circ} \mathrm{C}$ і різних значень числа Біо ( $\mathrm{Bi}$ ), величина абсолютної погрішності температури поверхні металу не перевищує $20^{\circ} \mathrm{C}$, що є достатньою для практичних результатів.

Окрім того, виявлено, що із збільшенням часу нагрівання значення настроювального коефіцієнта $\gamma\left(\tau_{\text {fix }}\right)$ зменшується і на деякий момент, залежно від величини числа $\mathrm{Bi}$, температура поверхні металу $T_{\text {sur }}$ дорівнюватиме температурі нагрівального середовища $T_{\text {w.e }}$, що відповідає наставанню періоду витримки металу в робочій камері печі $\left(T_{\mathrm{w} . \mathrm{e}}=\right.$ const $)$ i вирівнюванню температури щодо його перерізу $x$.

Під час оцінки часу, необхідного для завершення періоду витримки, виконують підставляння функції (1) до рівняння (3) та отримують нелінійне диференціальне рівняння першого порядку

$$
\frac{\partial \gamma(\tau)}{\partial \tau}+a_{\mathrm{m}} \frac{\gamma^{2}(\tau)}{x}=0
$$


Здійснюючи розподіл змінних величин у рівнянні (8) і його наступне інтегрування, а також задаючись кінцевим значенням $\gamma_{\text {fin }}(\tau)$ для пластини металу товщиною $S$ можна визначити час, що $є$ необхідним для проходження періоду витримки

$$
\tau_{\text {iso }}=\left\langle A+\frac{1}{\gamma_{\text {fin }}(\tau)}\right\rangle \cdot \frac{S}{a_{\mathrm{m}}} .
$$

Проте наявність складнощів, пов'язаних з визначенням постійної інтегрування $A$ у рівнянні (9), не дозволяє виконати чисельні розрахунки.

Під ча визначенні взаємозв'язку між розподілом температури та дією, що управляє, а також рівнями управління і моментами перемикання теплового навантаження печі у режимах нагрівання, виконували перерахунок розподілу температури металу на іiї середньомасову величину.

Рівняння (1), (3) і (7) описують математичну модель, що дозволяс обчислити поточні значення показників якості нагрівання металу, проте залишаються проблеми, пов'язані з визначенням коефіцієнта $\alpha_{\Sigma}$, необхідного для розрахунків критерію $\mathrm{Bi}$.

Виходячи 3 того, що кожному розподілу температури металу відповідає певна середньомасова температура $\bar{T}$, можна записати

$$
\bar{T}(\tau)=\frac{\grave{O}_{\mathrm{sur}}(\tau) \cdot\langle 1-\exp [\gamma(\tau)] \cdot S\rangle}{S \cdot \gamma(\tau)} .
$$

3 іншого боку, розглядаючи процес нагрівання металу як акумуляцію теплоти відповідно до рівняння [9]

$$
\frac{d \bar{T}}{d \tau}=\frac{\alpha_{\Sigma} \cdot K_{\mathrm{F}}}{K_{\mathrm{m}} \cdot S \cdot \rho_{\mathrm{m}} \cdot c_{\mathrm{m}}} \cdot\left(T_{\mathrm{sur}}-\bar{T}\right),
$$

де $K_{\mathrm{F}}, K_{\mathrm{m}}$ - коефіцієнти форми та масивності зливка відповідно, 一 й позначаючи постійну часу нагрівання $\grave{O}_{\mathrm{h}}$ як $\grave{O}_{\mathrm{h}}=\frac{K_{\mathrm{m}} \cdot S \cdot \rho_{\mathrm{m}} \cdot c_{\mathrm{m}}}{\alpha_{\Sigma} \cdot K_{\mathrm{F}}}$ можна подати температуру $\bar{T}$ як розв'язання рівняння (8) за початкової температури $\bar{T}\left(\tau_{\text {ini }}\right)$ :

$$
\bar{T}(\tau)=\left[\bar{T}\left(\tau_{\text {ini }}\right)-T_{\text {w.e }}(\tau)\right] \cdot \exp \left(-\frac{1}{T} \cdot \tau\right)+T_{\mathrm{h}}(\tau) .
$$

Приймаючи, що середня температура щодо товщини зливка відповідає її середньомасовій величині, а також прирівнюючи праві частини рівнянь (10) і (12), отримують взаємозв'язок параметрів $T_{\text {sur }}(\tau)$ i $\gamma(\tau)$ д дією $\dot{O}_{\text {w.e }}(\tau)$, що управляє, у часі, тобто оптимізаційну математичну модель у виді.

$$
\grave{O}_{\mathrm{w} . \mathrm{e}}(\tau)=\frac{T_{\mathrm{h}}(\tau) \cdot\langle 1-\exp [-\gamma(\tau) \cdot S]\rangle-S \cdot \gamma(\tau) \cdot \bar{T}\left(\tau_{\text {ini }}\right) \cdot \exp \left(-\frac{\tau}{T_{\mathrm{h}}}\right)}{S \cdot \gamma(\tau) \cdot\left[1-\exp \left(-\frac{\tau}{T_{\mathrm{h}}}\right)\right]} .
$$

Виходячи з того, що оптимальне щодо швидкодії управління є кусково-сталою функцією часу [9], а температура нагрівального середовища змінюється від гранично-можливої величини до значення, що відповідає заданій температурі поверхні металу, розробку алгоритму управління зводять до визначення моментів перемикання теплового навантаження печі, що можна обчислити з використанням формули

$$
\tau=T_{\mathrm{h}} \cdot \ln \left[\frac{T_{\mathrm{ini}}-\bar{T}\left(\tau_{\mathrm{ini}}\right)}{T_{\mathrm{w} . \mathrm{e}}-\frac{T_{\mathrm{sur}}}{S \cdot \gamma(\tau)} \cdot|1-\exp [-\gamma(\tau) \cdot S]|}\right]
$$


Ідентифікацію математичної моделі виконують за результатами вимірювання теплового навантаження печі. Як показано у замкнених системах регулювання температури [11], теплове навантаження печі змінюється залежно від температури в робочій камері, у цей час швидкість іiі змінювання $G_{\mathrm{w} . \mathrm{e}} \epsilon$ пропорційною швидкості нагрівання металу

$$
\frac{d G_{\mathrm{W} . \mathrm{e}}}{d \tau}=A \cdot \frac{1}{T_{\mathrm{m}}} \cdot \exp \left(-\frac{\tau}{T_{\mathrm{h}}}\right)
$$

За величиною відношення швидкостей нагрівання металу для двох моментів часу $W_{\tau_{i}}$ можна оцінити величину параметра $\grave{O}_{\mathrm{h}}$ :

$$
\grave{O}_{\mathrm{h}}=\Delta \tau \cdot \ln \left(\frac{W_{\tau_{2}}}{W_{\tau_{1}}}\right),
$$

де $\Delta \tau-$ інтервал часу ідентифікації, що дозволяє забезпечити урахування реальних значень параметра $\grave{O}_{\mathrm{h}}$, що є індивідуальним для кожної садки металу та системи «піч — метал» у ціломy.

Як початкові дані під час моделювання задають теплофізичні параметри садки металу, обмеження за швидкості його нагрівання, температуру печі, початковий і кінцевий розподіл температури щодо перерізу металу $T\left(x, \tau_{0}\right)$ і $T\left(x, \tau_{\text {end }}\right)$.

За результатами розрахунків визначають температурно-часовий режим, за яким у металі забезпечують заданий розподіл температури протягом мінімального проміжку часу: $T\left(x, \tau_{0}\right) \Rightarrow T\left(x, \tau_{\text {end }}\right)$ за $\tau_{\mathrm{h}}=\min$.

Рівень дій, що управляють, приймають максимально можливим з урахуванням обмежень за швидкості нагрівання металу на його першому ступені, допустимої температури футерівки печі та максимальної продуктивності пальників - на другому ступені, а також технологічно заданої температури поверхні металу — на третьому ступені.

Для термічно тонких тіл ( $\mathrm{Bi}<0,25, \gamma(\tau)=0)$ температуру поверхні $T_{\text {sur }}(\tau)$ приймають рівною його середньомасовій температурі $\bar{T}(\tau)$.

3 теорії оптимальних систем з розподіленими параметрами [12] відомо, що управління в таких системах $є$ кусково-сталою функцією часу з двома рівнями постійності $U_{1}$ i $U_{2}$ та обчислення зводять до визначення величини їх рівнів, а також моментів перемикання $\tau_{1} \mathrm{i} \tau_{2}$.

Дія, що управляє, на підставі принципу суперпозиції є еквівалентною дії, що складається $3 T_{\text {sur,max }}$ в діапазоні $0 \leq \tau \leq \tau_{1}$ і $3 T_{\text {sur,min }}$ протягом часу $\tau_{1} \leq \tau \leq \tau_{1}+\tau_{2}$. У зв'язку з цим кінцевий розподіл температури в металі на момент часу $\tau_{1}+\tau_{2}$ можна розглядати у вигляді двох компонентів:

- змінювання іiі розподілу за дією $T_{\text {sur,max }}-T_{0}(x)$, що управляє, протягом часу $0 \leq \tau \leq \tau_{1}$

- змінювання іiі розподілу за дією $T_{\text {sur,min }}-T_{0}(x)$, що управляє, протягом часу $\tau_{1} \leq \tau \leq \tau_{1}+\tau_{2}$.

Під час завдання необхідного розподілу температури у металі застосовують метод прямих [11], відповідно до якого його товщину [0;S] поділяють точками $x_{1}=0,25 S$ і $x_{2}=0,75 S$ на окремі ділянки, а розв'язання виконують методом послідовних наближень.

Як перше наближення вважають, що величина параметра $\tau_{2} \in$ настільки малою, що змінювання температури у точці $x_{2}=0,75 S$ не відбувається. Тоді визначають інтервал часу $\tau_{1}+\tau_{2}$, де для точки $x=S$ мають температуру $T_{\text {end }}(x)-T_{0}(x)$. Для цього задають розподіл температури у вигляді експоненти (1) так, щоб температура у точці $x=S$ дорівнювала кінцевому 
iii значенню $T_{\text {end }}(x)-T_{0}(x)$ за максимально допустимої величини температури поверхні $T_{\text {sur,max }}$.

Показник ступеня експоненти $\gamma\left(\tau_{1}+\tau_{2}\right)$ обчислюють за формулою

$$
\gamma\left(\tau_{1}+\tau_{2}\right)=\frac{1}{\mathrm{~S}} \cdot \ln \left(\frac{T_{\text {sur,max }}}{T_{\text {end }}}\right) .
$$

Відповідно до формули (7) виконують перерахунки температури поверхні металу $T_{\text {sur,max }}$ на температуру в печі:

$$
T_{\text {sur,max }}=\frac{\mathrm{Bi}+\gamma\left(\tau_{1}+\tau_{2}\right)}{\mathrm{Bi}} \cdot T_{\text {w.e, } \max } .
$$

На рис. 1 подано компоненти температури металу, яку розраховують за координатою $x$, а також початковий і результуючий розподіл його температури.

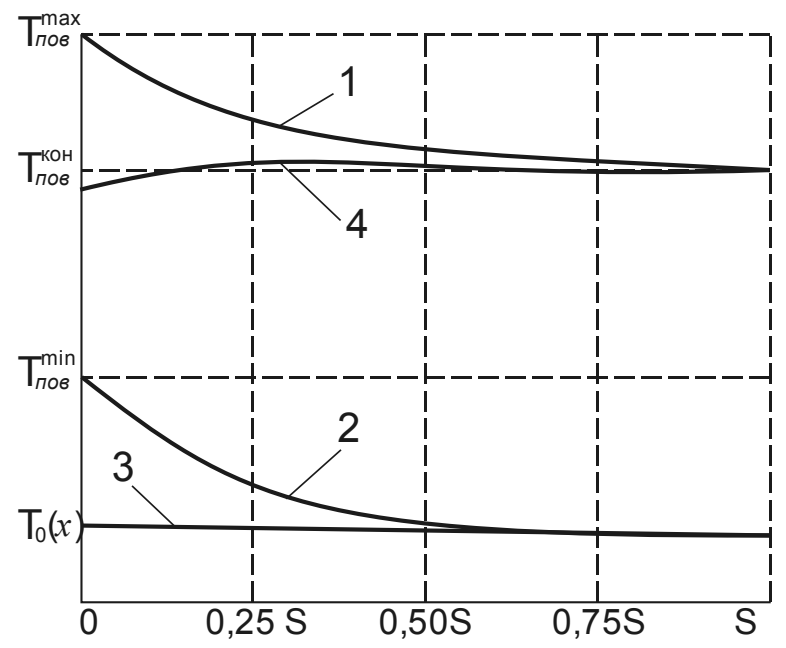

Рuc. 1. Розподіл температури щодо перерізу зливка: 1, 2 - розподіл температури за управлінням $U_{1}$ і $U_{2}, 3,4$ - початковий і кінцевий розподіл температури

3 рівняння (1) визначають температуру в точках $x_{1}=0,25 S$ і $x_{2}=0,75 S$, а також перевищення температури $\Delta T$ iї заданої кінцевої величини:

$$
\begin{gathered}
\Delta T(0,25 S)=T_{\text {sur,max }} \cdot \exp \left[-0,25 \gamma \cdot\left(\tau_{1}+\tau_{2}\right)\right]-T_{\text {end }}(0,25 S) ; \\
\Delta T(0,75 S)=T_{\text {sur,max }} \cdot \exp \left[-0,75 \gamma \cdot\left(\tau_{1}+\tau_{2}\right)\right]-T_{\text {end }}(0,75 S) .
\end{gathered}
$$

Задають необхідний розподіл температури під дією управління $U_{2}$ так, щоб температура $T(0,25 S)=\Delta T(0,25 S)$ і $T(0,75 S)=\Delta T(0,75 S)$, а. показник експоненти $\gamma\left(\tau_{2}\right)$ визначають із співвідношення $\Delta T=0,25 S$ і $\Delta T=0,75 S$.

$$
\gamma\left(\tau_{2}\right)=\frac{2}{3} \cdot \ln \left[\frac{\Delta T(0,25 S)}{\Delta T(0,75 S)}\right] .
$$

Адекватність математичної моделі встановлювали зіставленням оптимальних за швидкодії алгоритмів управління з результатами розрахунку на моделях інших авторів. Виявлено, що за пропонованим алгоритмом управління моменти перемикання теплового навантаження печі складають: для першого рівня $\tau_{1}=1,41$ ч, для другого рівня $\tau_{2}=0,12$ ч, а під час використання номограм роботи [12] відповідно $\tau_{1}=1,40$ ч і $\tau_{2}=0,13$ ч, тобто зафіксовано достатню збіжність результатів. 


\section{Висновки}

Запропоновано математичну модель і розроблено алгоритм розрахунку нагрівання масивних зливків у термічних полуменевих печах камерного типу, які можна використовувати для управління процесом нагрівання металу під термічну обробку з двома і більше рівнями постійності.

\section{Список використаної літератури}

1. Ольшанский В. М. Проблема энергосбережения при производстве проката на металлургических предприятиях Украины / В. М. Ольшанский // Металлургическая теплотехника: сб. научн. трудов. - Днепропетровск: ГМАУ, 1999. - Т. 2. - С. 63-66.

2. Панферов В. И. Адаптивные системы контроля качества нагрева металла в печах / В. И. Панферов // Известия Вузов. Черная металлургия. - 2002. - № 4. - С. 42-45.

3. Ольшанский В. М. Разработка оптимальных режимов нагрева металла в камерных печах / В. М. Ольшанский, Т. Н. Шемет // Металлургическая теплотехника: сб. научн. трудов. Днепропетровск: ГМАУ, 1989. - Т. 2. - С. 192-193.

4. Тайц Н. Ю. Выбор режима нагрева металла ч минимальным расходом топлива / Н. Ю. Тайц, Л. А. Гузов, В. М. Ольшанский и др. // Известия Вузов. Черная металлургия. - 1974. - № 4. C. 164-167.

5. Решетник, И. С. Математическое моделирование нагрева металлов камерных печах / И. С. Решетник, А. И. Литвин, С. И. Решетник // Математические методы тепломассопереноса: сб. научн. трудов. - Днепропетровск: ДГУ, 1983. - С. 39-43.

6. Бухмиров В. В. Математическая модель нагревательной печи периодического действия / В. В. Бухмиров, С. А. Крупенников, С. В. Носова // Металлургическая теплотехника: сб. научн. трудов. - Днепропетровск: НМАУ, 2002. - Вып. 7. - С. 24-32.

7. Арутюнов В. А. Математическое моделирование тепловой работы промышленных печей / В. А. Арутюнов, В. В. Бухмиров, С. А. Крупенников. - М.: Металлургия, 1990. - 239 с.

8. Лисиенко В.Г. Математическое моделирование теплообмена в печах и агрегатах / В. Г. Лисиенко, В. В. Волков, А. Л. Гончаров. - К.: Наукова думка, 1984. - 230 с.

9. Бутковский А. Г. Теория оптимального управления системами с распределенными параметрами / А. Г. Бутковский. - М.: Наука, 1965. - 476 с.

10. Беляев Н. М. Основы теплопередачи / Н. М. Беляев. - К.: Выща школа, 1989. - 342 с.

11. Ревун М. П. Адаптивные системы управления процессами нагрева металлов / М. П. Ревун, А. К. Соколов. - Запорожье: РИО ЗГИА, 1998. - 352 с.

12. Бутковский А. Г. Методы управления системами с распределенными параметрами / А. Г. Бутковский. - М.: Наука, 1975. -508 с. 